\title{
PERANCANGAN SISTEM INFORMASI SERBA USAHA PADA KOPERASI TANGERANG
}

\author{
I Gusti Made Karmawan \\ Program Information System Audit, School of Information System, BINUS University, Jakarta \\ Jl. Kebon Jeruk Raya No. 27, Kebon Jeruk Jakarta Barat 11530 \\ sudida@binus.edu;karmawan65@yahoo.co.id
}

\begin{abstract}
Savings and loan cooperative or credit and trade unions is part of a Multipurpose Cooperative Enterprises engaged in the field of small - medium businesses. Capitalization is achieved through the savings of its members in a way that is easy, inexpensive, fast, and accurate for the purpose of productivity and prosperity for the members. This study was conducted to design information systems, computer-based savings and loan in order to help improve performance. The purpose of information system design in Tangerang savings and loan cooperatives are providing computerized system of savings and loan and trading. The methodology used in the design of information systems is developing a System Life Cycle (SDLC). The results of this study indicate that the use of information systems Savings and Loans, Trade, and Services can provide solutions to the activities undertaken in terms of speed, precision and accuracy in carrying out data processing activities of savings and loan in order to get optimal results.
\end{abstract}

Keywords: Information Systems, savings and loans, trade, SDLC, cooperative

\begin{abstract}
ABSTRAK
Koperasi simpan pinjam atau koperasi kredit dan dagang adalah bagian dari Koperasi Serba Usaha yang bergerak dalam lapangan usaha kecil- menengah, pembentukan modal dicapai melalui tabungan-tabungan para anggotanya dengan cara yang mudah, murah, cepat, dan tepat untuk tujuan produktivitas dan kesejahteraan bagi para anggota. Penelitian ini dilakukan untuk merancang sistem informasi simpan pinjam yang berbasis komputer agar dapat membantu meningkatkan kinerja. Tujuan dari perancangan sistem informasi Koperasi simpan pinjam di Tangerang adalah menyediakan sistem simpan pinjam, dan perdagangan, yang terkomputerisasi. Metodologi yang digunakan dalam perancangan sistem informasi ini adalah Siklus Hidup Pengembagan Sistem (SDLC). Hasil Penelitian ini menunjukan bahwa penggunaan sistem informasi Simpan Pinjam, Perdagangan, dan Jasa dapat memberikan solusi mengenai aktivitas yang dilakukan dalam hal: kecepatan, ketepatan dan keakuratan dalam melaksanakan pengolahan data simpan pinjam agar mendapat hasil yang optimal.
\end{abstract}

Kata kunci: Sistem Informasi, simpan pinjam, perdagangan, SDLC, koperasi 


\section{PENDAHULUAN}

Koperasi Serba Usaha adalah salah satu organisasi koperasi yang salah satu kegiatan utamanya adalah menyediakan jasa simpan pinjam dan perdagangan bagi para anggotanya dan luar anggota. Pada dasarnya koperasi serba usaha ini merupakan suatu lembaga ekonomi kecil-menengah yang sangat penting bagi masyarakat. Koperasi serba usaha merupakan suatu usaha bersama yang berlandaskan asas kekeluargaan untuk meningkatkan kesejahteraan anggota. Koperasi simpan pinjam atau koperasi kredit dan dagang adalah bergerak dalam lapangan usaha kecil-menengah, pembentukan modal dicapai melalui tabungan-tabungan para anggotanya dengan cara yang mudah, murah, cepat, dan tepat untuk tujuan produktivitas dan kesejahteraan bagi para anggota (Anggraeni, Retnadi \&Kurniawati, 2012).

Melalui proses simpan pinjam di Koperasi Serba Usaha diperoleh keterangan bahwa sistem yang sedang berjalan di Koperasi masih dilakukan secara manual, semua dokumen dikendalikan dan dicatat secara manual, sehingga akan berpengaruh pada efisiensi waktu informasi yang akan diterima oleh anggota, dan tenaga kerja. Keamanan dan pengolahan data akan menjadi lambat dan diragukan kebenarannya karena tidak menutup kemungkinan terdapat kecurangan yang disengaja maupun yang tidak disengaja dan manipulasi data transaksi.

Dari latar belakang yang telah diungkapkan di atas, maka tujuan dari penelitian ini adalah untuk merancang sistem informasi simpan pinjam yang berbasis komputer yang dapat membantu meningkatkan kinerja dan dapat mengakomodasi transaksi simpan pinjam di Koperasi Serba Usaha sehingga dapat memberikan solusi kecepatan, ketepatan, dan keakuratan dalam melakukan pengolah data transaksi simpan pinjam agar mendapatkan hasil yang optimal. Tujuan-tujuan tersebut secara lebih khusus adalah: (1) Melakukan analisis terhadap masalah-masalah yang mungkin terjadi pada sistem penjualan dan penerimaan kas sehingga dapat memperbaiki masalah-masalah yang ada. (2) Merancang sebuah sistem informasi akuntansi penjualan dan penerimaan kas yang baik dan dapat menghasilkan informasi-informasi yang dibutuhkan. (3) Meningkatkan efisiensi dan efektivitas koperasi dalam melakukan proses penjualan dan penerimaan kas.

\section{Sistem Informasi}

Sistem informasi adalah suatu sistem buatan manusia yang secara umum terdiri atas sekumpulan komponen berbasis komputer dan manual yang dibuat untuk menghimpun, menyimpan, dan mengelola data serta menyediakan informasi keluaran kepada para pemakai (Satzinger, Jackson \& Burd, 2012). Sistem informasi merupakan suatu sistem yang saling berkaitan dan berintegrasi satu sama lain dan bertujuan menyediakan informasi untuk mendukung operasi, manajemen dan fungsi pengambilan keputusan dalam suatu organisasi. Menurut Satzinger, Jackson \& Burd (2012), kegiatan di Sistem Informasi mencakup: (1) Input, menggambarkan suatu kegiatan untuk menyediakan data untuk diproses. (2) Proses, menggambarkan bagaimana suatu data di proses untuk menghasilkan suatu informasi yang bernilai tambah. (3) Output, suatu kegiatan untuk menghasilkan laporan dari proses diatas tersebut. (4) Penyimpanan, suatu kegiatan untuk memelihara dan menyimpan data. (5) Kontrol, ialah suatu aktivitas untuk menjamin bahwa sistem informasi tersebut berjalan sesuai dengan yang diharapkan.

\section{Definisi Koperasi}

Pada dasarnya koperasi merupakan suatu lembaga ekonomi yang penting dan diperlukan. Koperasi merupakan usaha bersama yang berlandaskan asas kekeluargaan untuk meningkatkan kesejahteraan anggota. Koperasi berasal dari bahasa Inggris co-operation, cooperative, atau bahasa Latin: coopere, atau dalam bahasa Belanda: cooperatie, cooperatieve, yang kurang lebih berarti 
bekerja bersama-sama, atau kerja sama, atau usaha bersama atau yang bersifat kerja sama. Dasar hukum keberadaan koperasi di Indonesia ada dalam pasal 33 UUD 1945 dan UU No.25 tahun 1992 tentang perkoperasian. Yang dimaksud dengan koperasi adalah: Badan usaha yang beranggotakan orang seorang atau badan hukum koperasi dengan melaksanakan kegiatannya berdasar prinsip koperasi, sekaligus sebagai gerakan ekonomi rakyat yang berdasar atas asas kekeluargaan (Subandi, 2010). Tujuan kopersai sebagaimana dikemukakan dalam pasal 3 UU No.25/1992 adalah sebagai berikut: Koperasi bertujuan memajukan kesejahteraan anggota pada khususnya dan pada masyarakat pada umumnya serta ikut membangun tatanan perekonomian nasional dalam rangka mewujudkan masyarakat yang maju, adil dan makmur berdasarkan Pancasila dan UUD 1945 (Subandi, 2010).

\section{METODE}

Metode ini merupakan salah satu model yang menggambarkan siklus hidup pengembangan perangkat lunak. Ini dilakukan bertahap dari awal sampai ke tahap berikutnya (Jogiyanto, H. M., 2007).

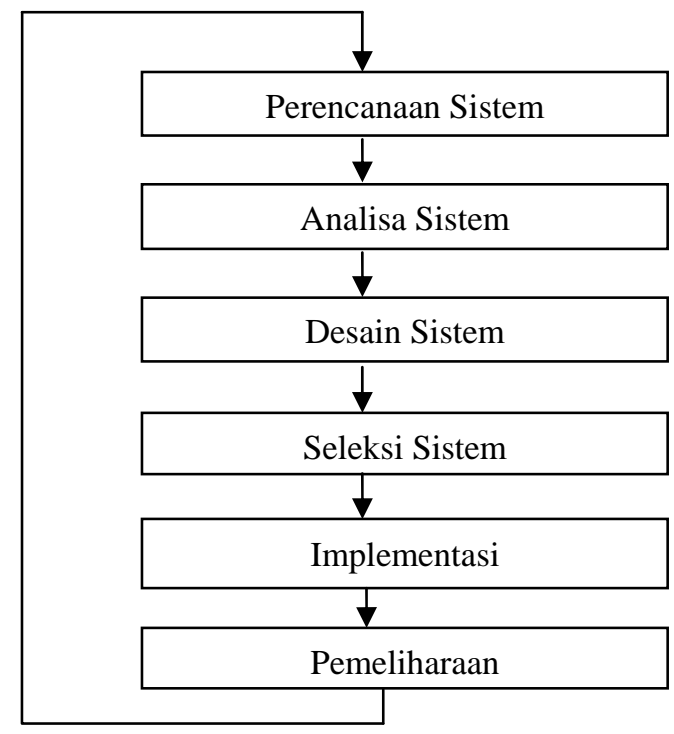

Gambar 1 Siklus Hidup Pengembangan Sistem

\section{HASIL DAN PEMBAHASAN}

\section{Mengidentifikasi Keputusan}

Sebagai dasar untuk mengidentifikasi keputusan maka dijelaskan melalui bagan alir serta prosedur simpan pinjam yang diuraikan sebagai berikut. Proses transaksi simpanan yang sedang berjalan digambarkan menggunakan flowchart sebagai berikut: 


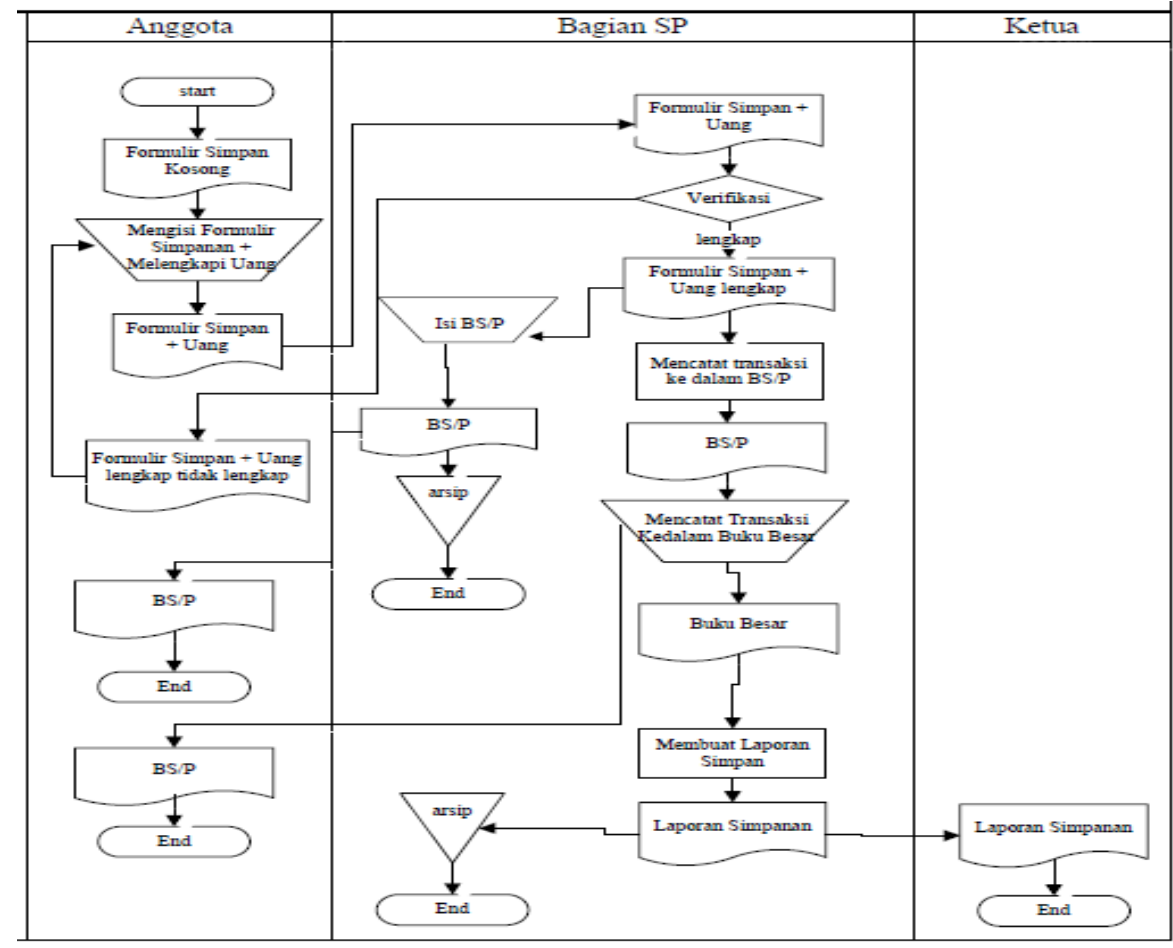

Gambar 2 Transaksi Simpanan yang Sedang Berjalan

Proses transaksi simpan pinjam yang sedang berjalan digambarkan menggunakan flowchart sebagai berikut:

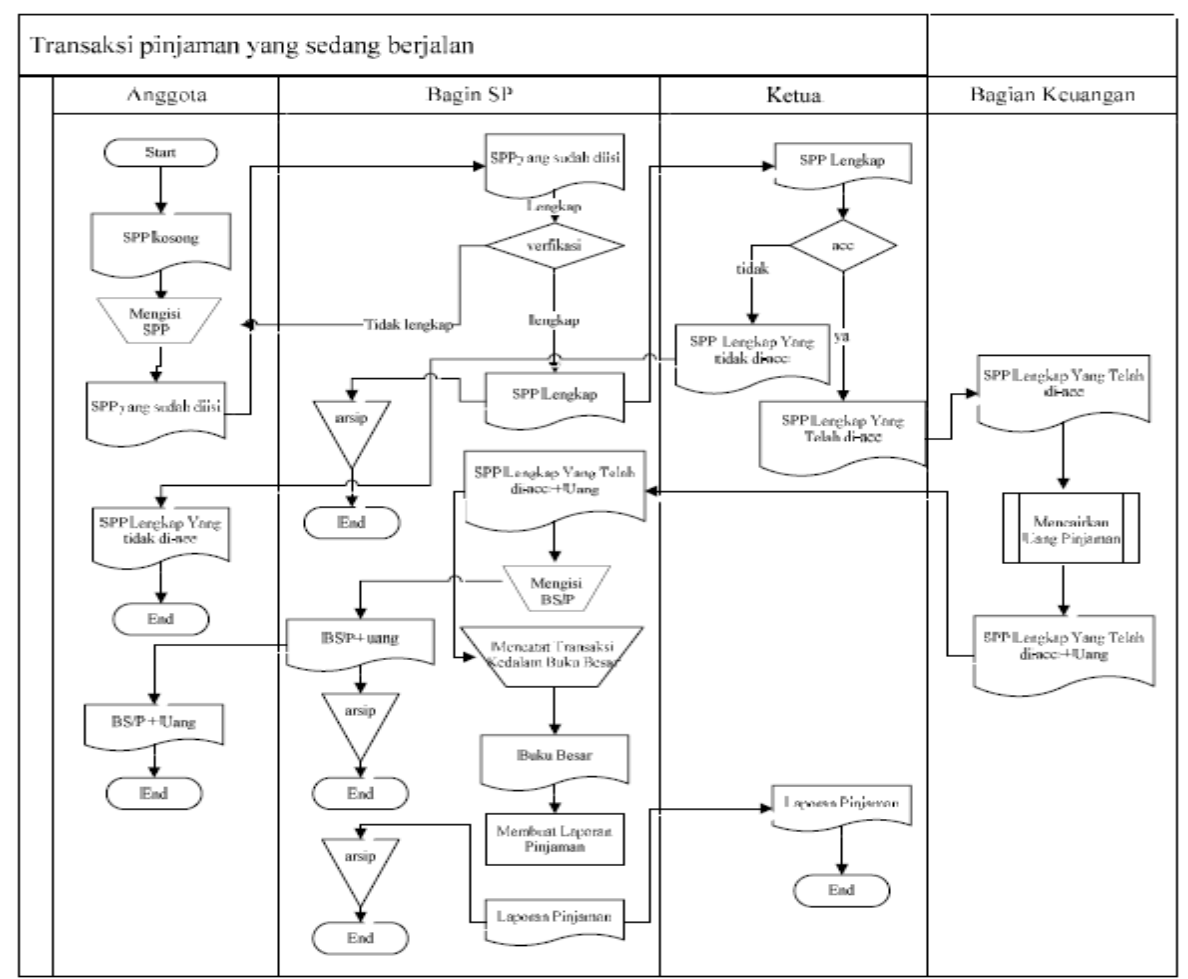

Gambar 3 Transaksi Pinjaman yang Sedang Berjalan 
Proses transaksi pembayaran angsuran yang sedang berjalan digambarkan menggunakan flowchart sebagai berikut:

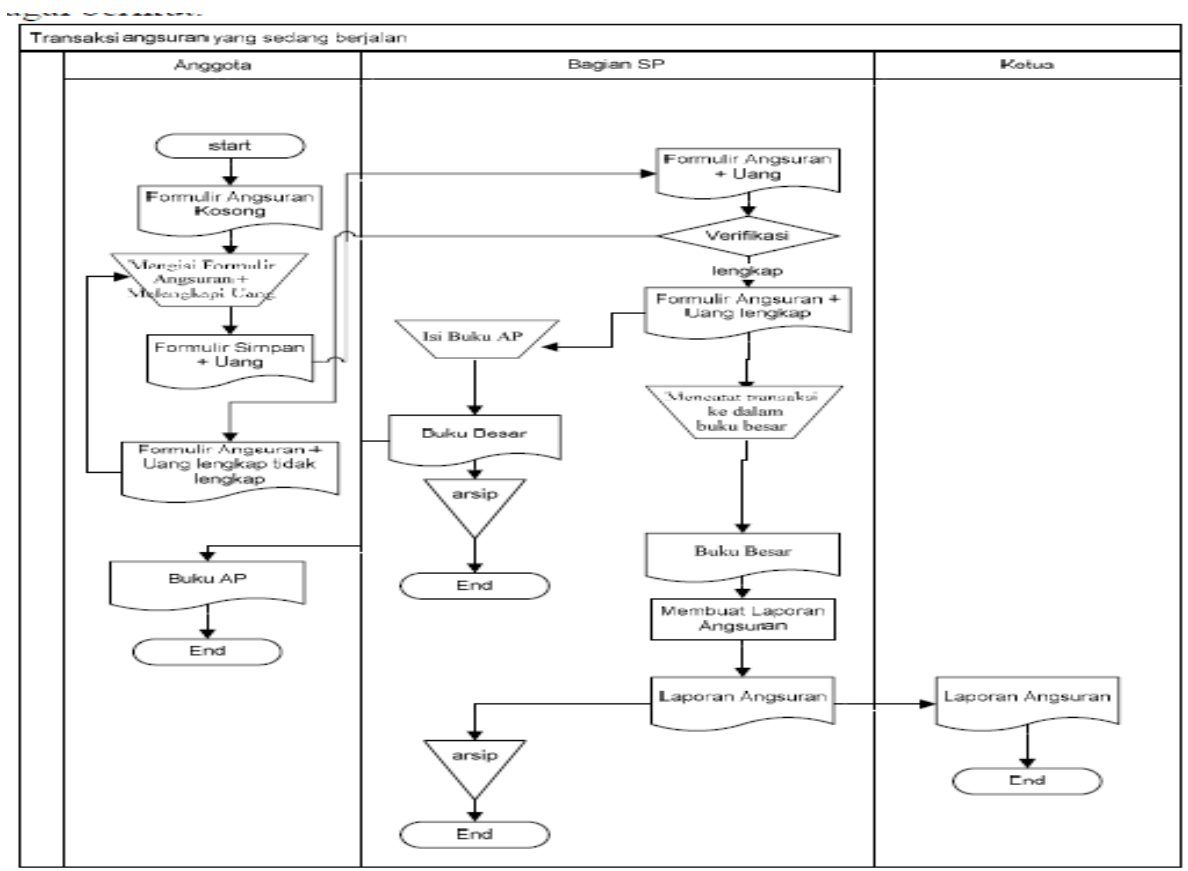

Gambar 4 Tansaksi Pembayaran Angsuran Pinjaman yang Sedang Berjalan

Proses transaksi simpanan yang diusulkan digambarkan menggunakan flowchart sebagai berikut:

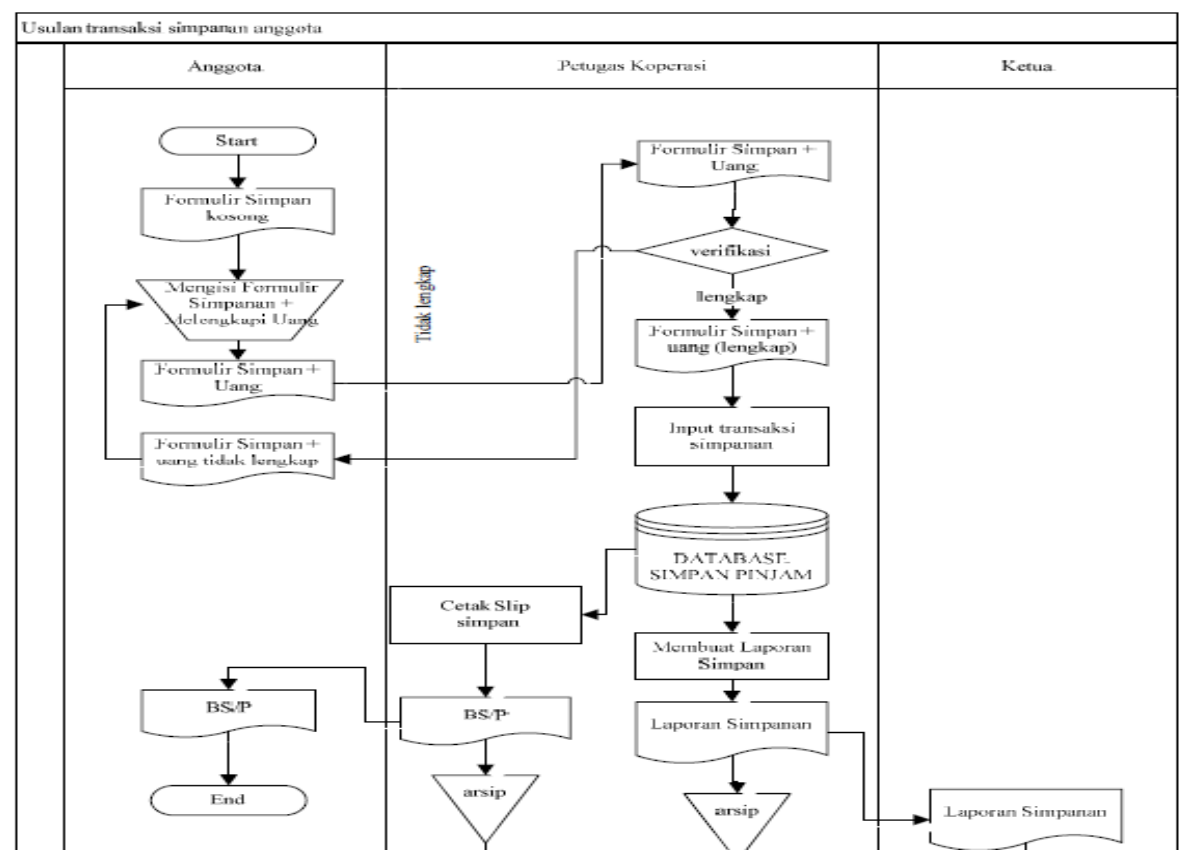

Gambar 5 Transaksi Simpanan pinjam yang Diusulkan 
Proses transaksi simpan pinjaman yang diusulkan digambarkan menggunakan flowchart sebagai berikut:

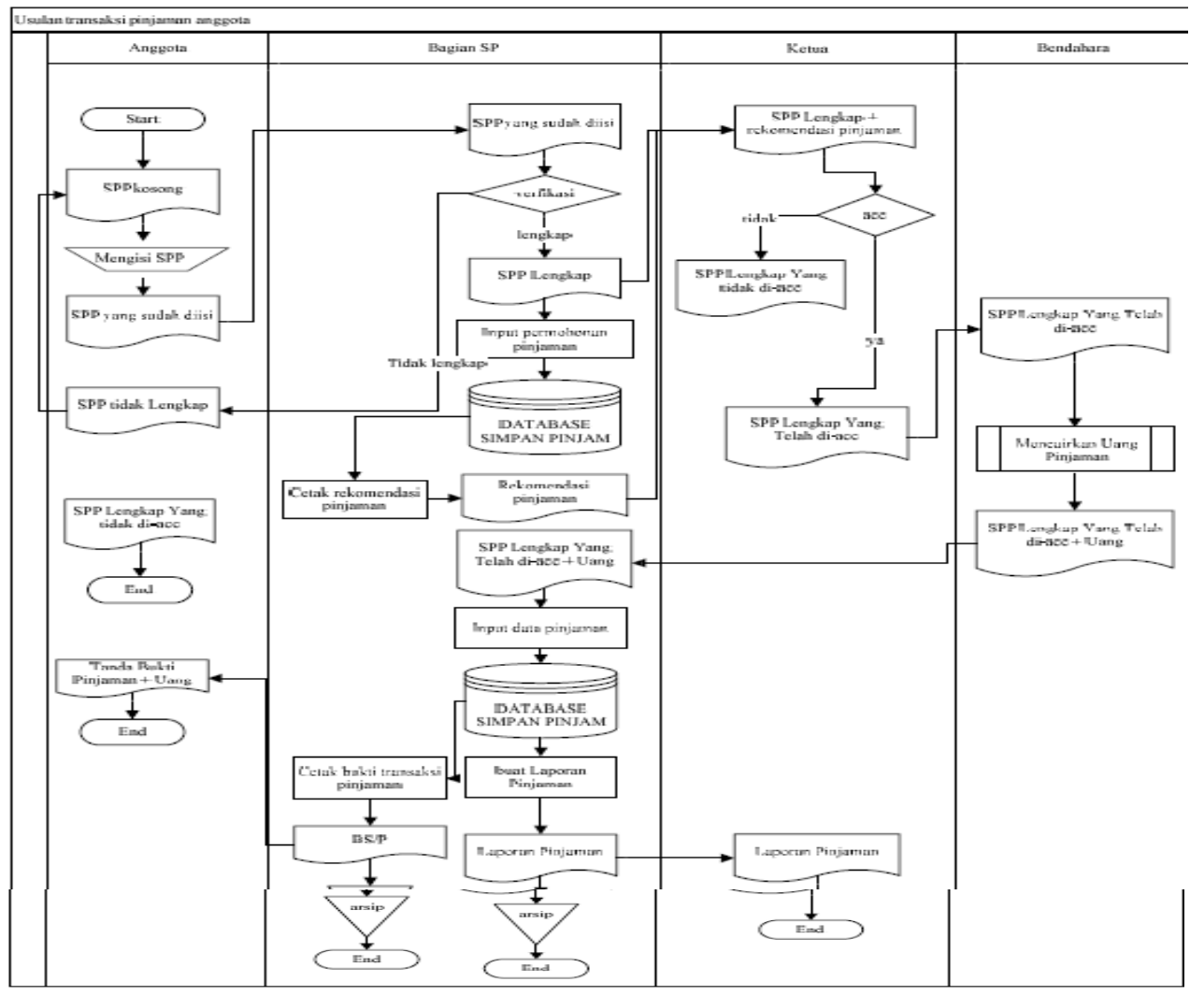

Gambar 6 Transaksi Pinjaman yang Diusulkan

Proses transaksi pembayaran angsuran yang diusulkan digambarkan menggunakan flowchart sebagai berikut:

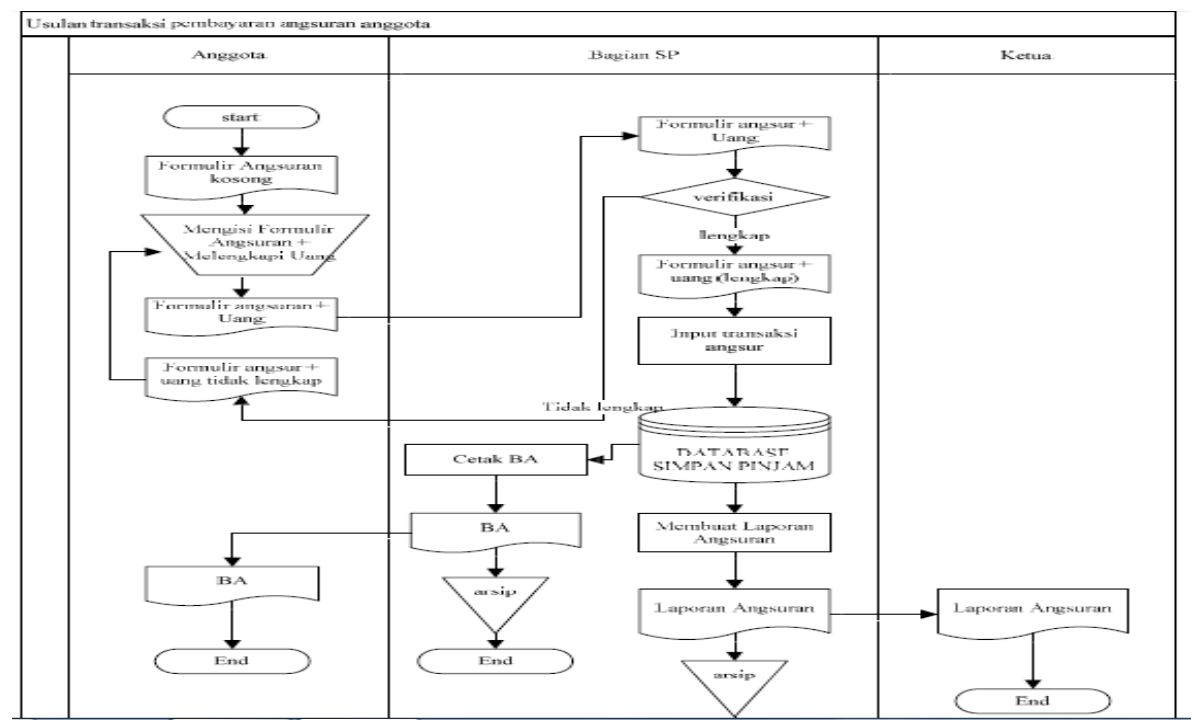

Gambar 7 Transaksi Pembayaran Angsuran yang Diusulkan 
Proses perhitungan SHU yang diusulkan digambarkan menggunakan flowchart sebagai berikut:

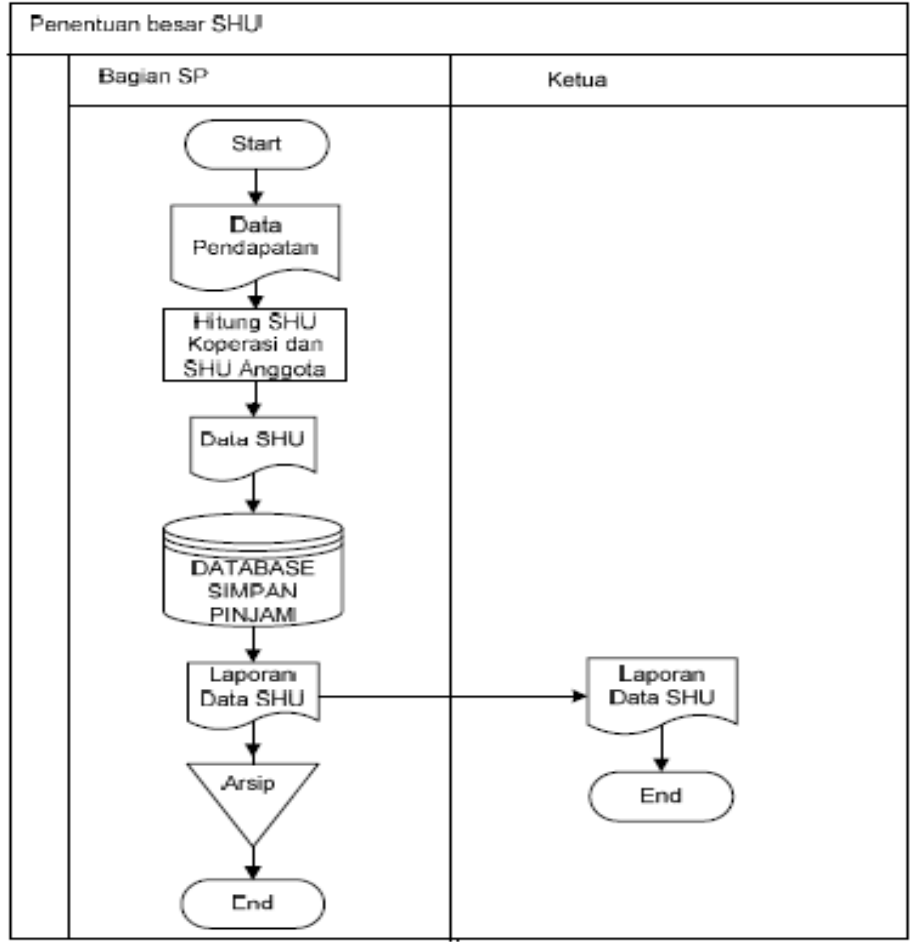

Gambar 8 Perhitungan SHU yang Diusulkan

Kelemahan Current Sistem proses simpan pinjam Koperasi Serba Usaha diperoleh dari informasi bahwa dalam sistem yang sedang berjalan, Koperasi masih melakikan pencatatan secara manual, sehingga berpengaruh pada efisiensi waktu dan tenaga. Keamanan dan pengolahan data juga diragukan kebenarannya karena tidak ada kemungkinan kecurangan yang disengaja maupun yang tidak disengaja.

Keunggulan Sistem Informasi Simpan Pinjam yang diusulkan adalah sistem informasi simpan pinjam yang berbasis komputer yang dapat membantu meningkatkan kinerja dan dapat mengakomodasi transaksi simpan pinjam di Koperasi sehingga dapat memberikan solusi kecepatan, ketepatan, dan keakuratan dalam melakukan pengolah data simpan pinjam agar mendapatkan hasil yang optimal. 


\section{Hasil Perancangan}

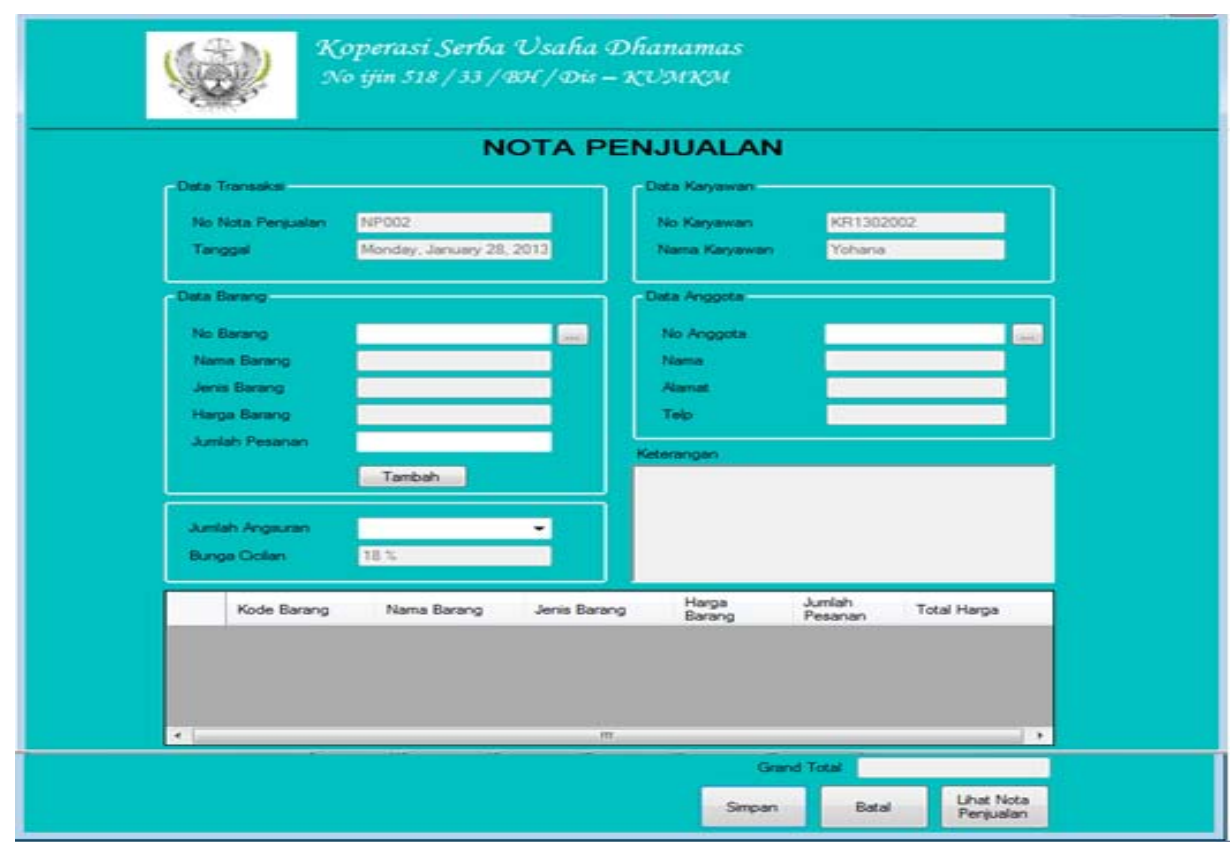

Gambar 9 Rancangan Layar Nota Penjualan

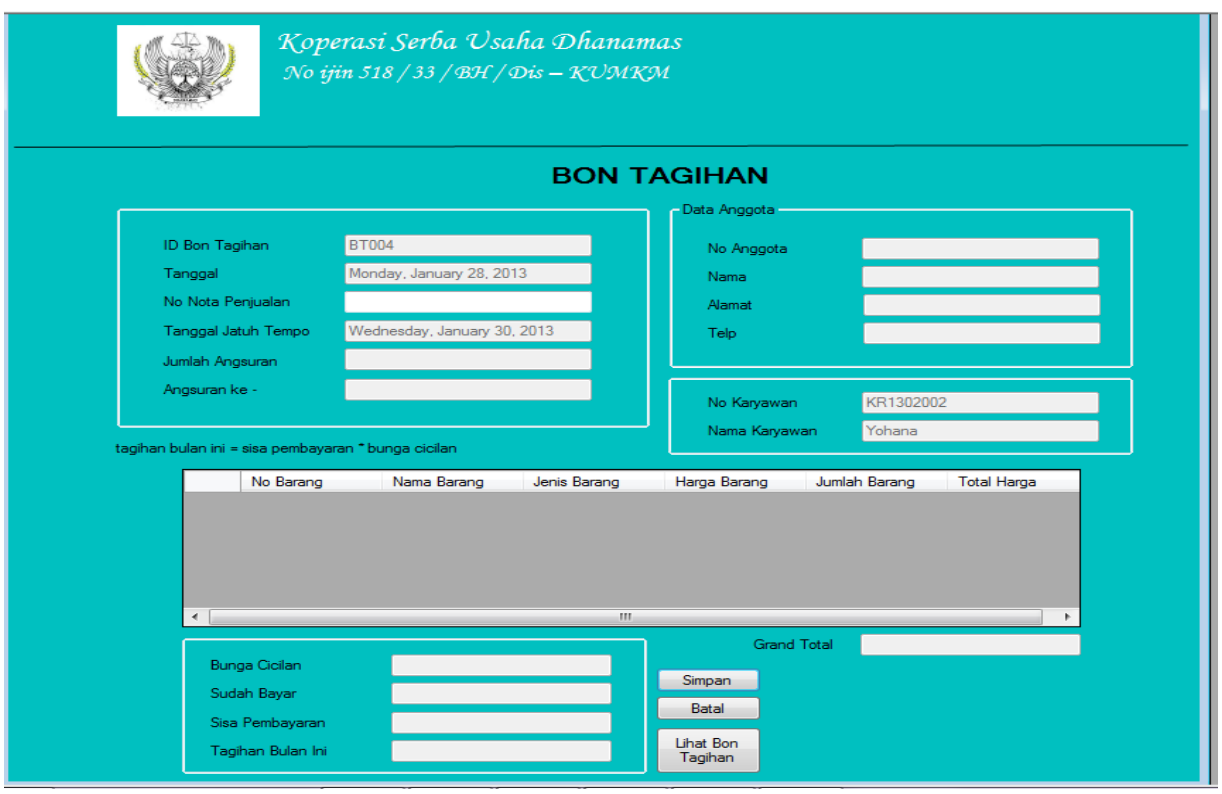

Gambar 10 Rancangan Layar Bon Tagihan 


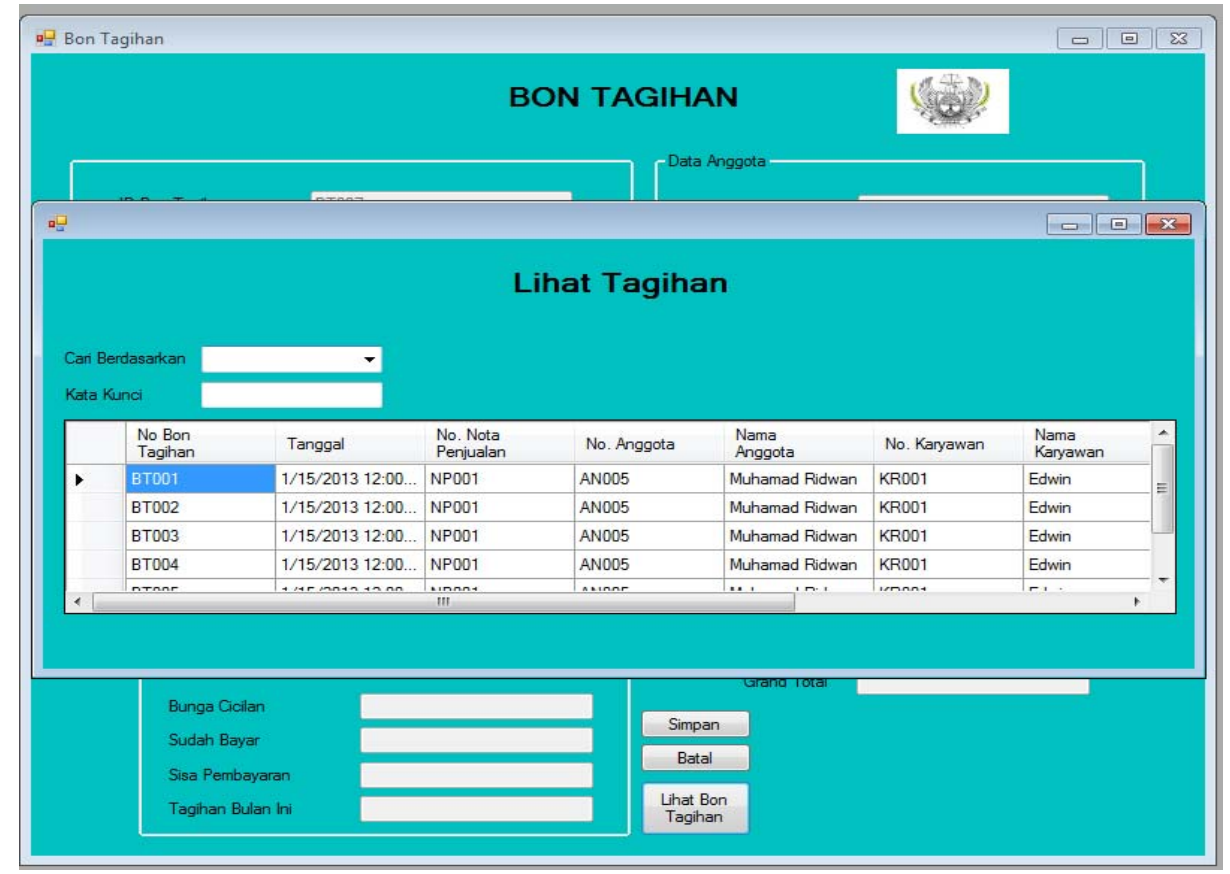

Gambar 11 Rancangan Layar Lihat Tagihan

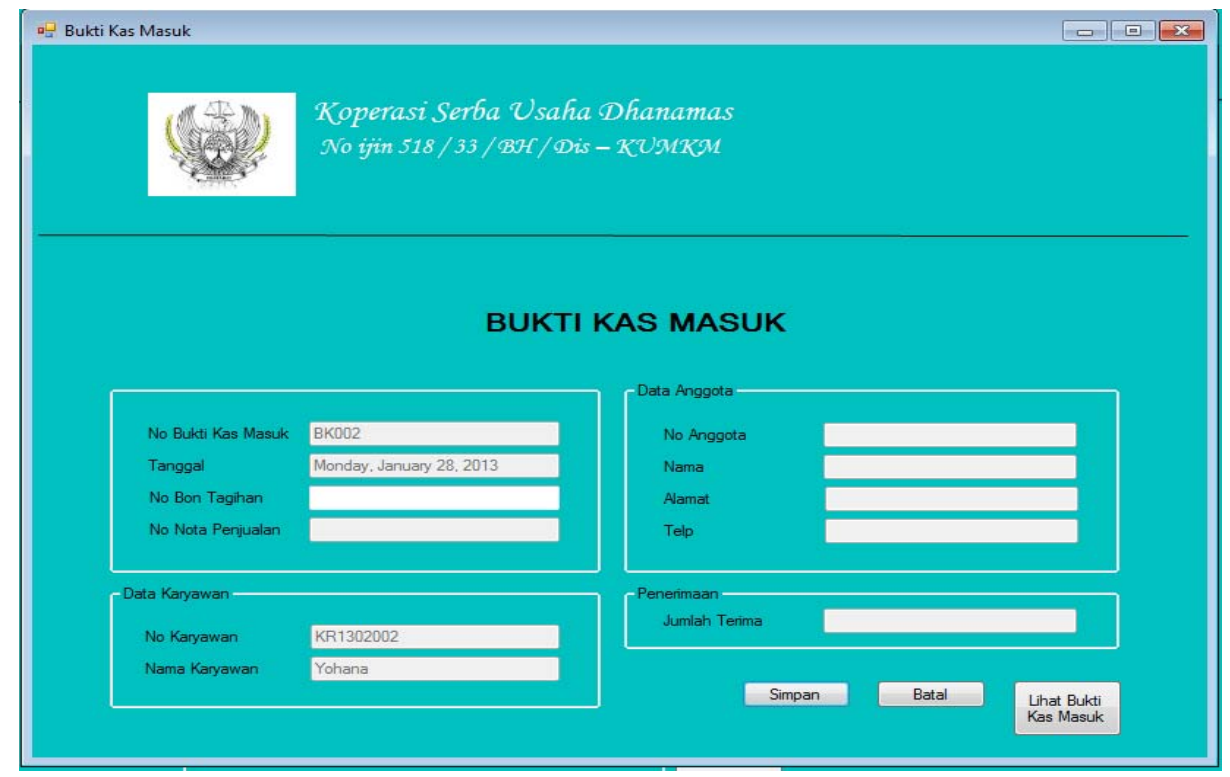

Gambar 12 Rancangan Layar Bukti Kas Masuk 


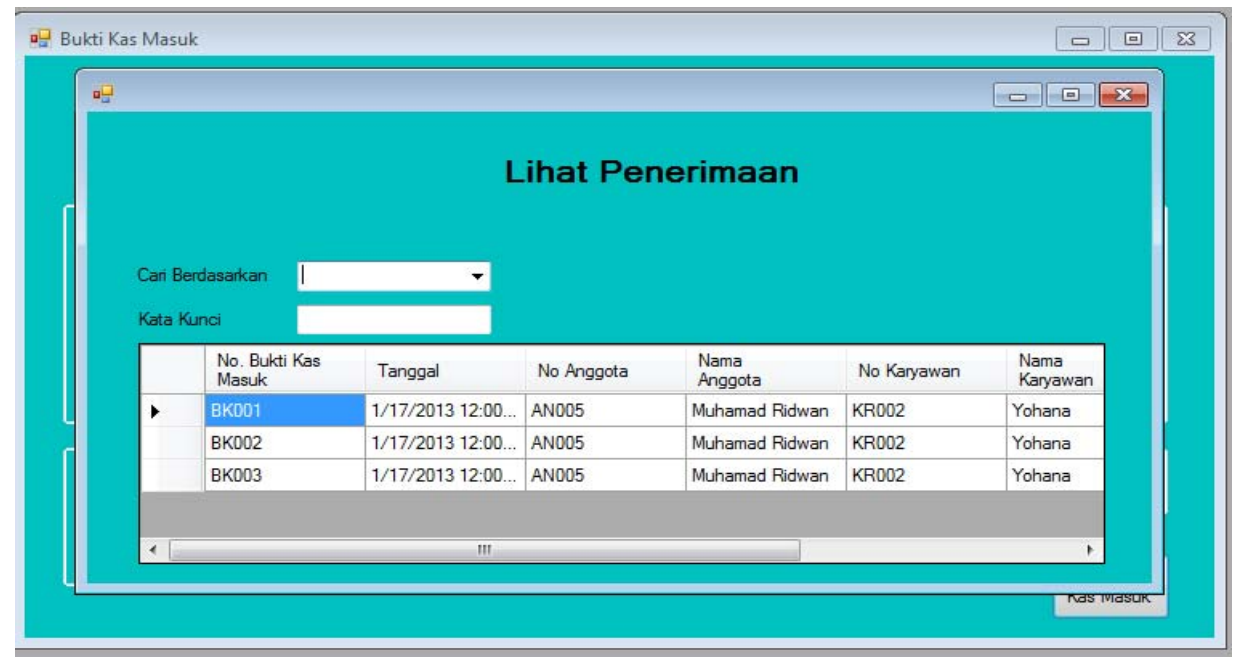

Gambar 13 Rancangan Layar Lihat Penerimaan

\section{SIMPULAN}

Berdasarkan hasil kajian dan pembahasan, tinjauan teori yang ada, kesimpulan yang diambil dari hasil analisis dan perancangan Sistem Informasi Simpan Pinjam pada Koperasi Serba Usaha ini adalah Aplikasi Sistem Informasi Simpan Pinjam ini dapat mempermudah kinerja petugas dalam mengakomodasi pencarian data serta pencatatan transaksi. Transaksi yang dilakukan oleh anggota baru serta anggota lama dapat dikontrol sehingga apabila ada transaksi yang dibutuhkan dapat dicari dengan waktu yang relatif singkat dan dapat segera diketahui oleh petugas karena tersedianya daftar transaksi yang berupa laporan transaksi per orang. Sistem menyediakan informasi yang dibutuhkan oleh Koperasi Serba Usaha, diantaranya yaitu informasi daftar anggota, daftar transaksi yang dilakukan seperti transaksi simpanan, pinjaman dan angsuran yang dilakukan oleh anggota beserta laporan yang diperlukan serta kwitansi-kwitansi dari setiap transaksi. Sistem Juga menyediakan informasi tentang perdagangan sembako.

\section{DAFTAR PUSTAKA}

Anggraeni, N., Retnadi, E., Kurniawati, R. (2012) 2012 Jurnal Koperasi Simpan Pinjam, 09(0)5, Sekolah Tinggi Teknologi Garut, ISSN: 2302-7339

Jogiyanto, H. M. (2007). Analisis dan Desain Sistem Informasi: Pendekatan Terstruktur Teori dan Praktik Aplikasi Bisnis. Jogyakarta: Andi.

Satzinger, J W., Jackson, R.B, Burd, S.D. (2012). System Analysis and Design in A Changing World. USA: Cengage Learning.

Subandi. (2010). Ekonomi Koperasi Teori dan Praktik. Bandung: Alfabeta. 